\title{
Cephalometric characteristics of Class III malocclusion In Brazilian individuals
}

\author{
Marcus Barreto Vasconcelos, Célia Regina Maio Pinzan-Vercelino, \\ Júlio de Araújo Gurgel, Fausto da Silva Bramante
}

Universidade Ceuma, Dental School, Department of Orthodontics, São Luís, MA, Brazil

\begin{abstract}
Aim: To evaluate the cephalometric characteristics of Class III malocclusion in Caucasian Brazilian subjects. Methods: The sample comprised 71 lateral cephalograms of individuals not previously submitted to any orthodontic treatment. The Class III group (experimental group) comprised 37 patients with bilateral Class III molar relationship and ANB lower than 1 degree, with a mean age of $21.76+3.89$ years (13 males and 24 females). The Class I group (control group) consisted of 34 patients with bilateral Class I molar relationship, ANB angle higher than or equal to $1^{\circ}$ and lower than $3^{\circ}$, with a mean age of $21.88+3.5$ years (12 males and 22 females). Dental, skeletal and soft tissue measurements were compared using the $t$ test for independent samples. Results: The results demonstrated that the Class III individuals showed significant differences in the cephalometric characteristics, except in vertical skeletal variables. The angular variables (SNA, SNB, ANB, SND, 1.1, 1.NA, 1.NB, IMPA, NA.Pog, H.NB) and the linear variables (Pog-Nperp, Co-Gn, 1-orbit, 1-NA, 1-NB, 1-NPog, 1-ANperp, FN-Pog, H-nose, Pog-NB, E menton) demonstrated statistically significant differences between groups. Conclusions: In Class III group, subjects presented maxilla with normal size, yet retruded in relation to the anterior cranial base; protruded mandible with increased size; and concave skeletal and soft tissue profiles. The maxillary incisors were protruded and buccally tipped, and the mandibular incisors were retruded and lingually tipped. Higher prevalence of mandibular prognathism (67.6\%) was observed in the Class III group.
\end{abstract}

Keywords: orthodontics; cephalometry; malocclusion, Angle Class III.

\section{Introduction}

Received for publication: September 15, 2014 Accepted: December 16, 2014

Correspondence to: Célia Regina Maio Pinzan-Vercelino Alameda dos Sabiás, 58. Portal dos Pássaros CEP:18550-000 Boituva, SP, Brasil Phone: +55 1533634976 E-mail: cepinzan@hotmail.com
Despite its low prevalence, Angle Class III malocclusion is a constant concern for the orthodontist, due to its complexity ${ }^{1}$, high esthetic involvement ${ }^{1-3}$ and difficult prognosis ${ }^{4}$.

The Class III malocclusion has a strong influence from heredity ${ }^{2}$ and specific morphological characteristics that remain constant within some ethnic groups. Some recent studies ${ }^{5-9}$ has shown that genetic factors contribute to Class III development. Thus, the utilization of a pre-established standard with norms obtained in other regions, without considering the ethnic differences, has been defective and unpredictable.

Therefore, knowledge on the characteristics of this malocclusion is fundamental for the orthodontist, allowing a more accurate diagnosis ${ }^{10}$, appropriate treatment planning ${ }^{11}$, greater therapeutic efficiency and post-treatment stability ${ }^{12}$. The orthodontist should necessarily know the facial morphological characteristics of the different ethnic groups for full achievement of the patient's expectations and treatment goals. 
Also, the treatment should maintain the ethnic characteristics of each patient, since the maxillomandibular and dental relationships present wide variety within the normal range. This avoids changes in facial harmony, consequently maintaining the patient coherent with his or her phenotypic pattern.

Few studies ${ }^{2,12-13}$ have investigated Class III malocclusion characteristics, especially in specific ethnic groups. Therefore, in order to provide more specific information regarding this type of malocclusion in Caucasian Brazilian individuals, this comparative cephalometric study was designed.

\section{Material and methods}

This study was approved by the Institutional Review Board of University Ceuma (São Luís, MA, Brazil), under protocol number 00211-10.

The sample comprised the initial orthodontic records of 71 Caucasian Brazilian individuals that had not been previously submitted to any orthodontic treatment. The subjects were of both genders ( 25 males and 46 females), with mean age of 21.58 years +3.33 (minimum 18 years and maximum 30 years), selected among 8.051 patients attended a private imaging clinic.

The inclusion criteria were: Caucasian Brazilian individuals; straight to slightly convex profile or concave facial profile; Class I or full cusp Class III molar and canine relationship; presence of all teeth up to the second molars, erupted and occluding; no supernumerary teeth; no severe or moderate facial asymmetry; no impacted teeth; absence of significant anomalies in tooth size and/or shape; and age between 18 and 30 years $^{2,4,14-15}$.

The facial profile evaluation was combined with cephalometric analysis for accurate diagnosis ${ }^{12}$. Two experienced orthodontists evaluated all participants, individually and at different moments. The participants were only included in the sample when there was agreement between the two examiners.

The study subjects were divided into two groups, according to the facial profile, malocclusion and ANB:

Class III group (experimental): 37 individuals with concave facial profile, bilateral Angle Class III molar relationship and ANB angle lower than $1^{\circ}$.

Class I group (control): 34 subjects that showed straight to slightly convex profile; bilateral Angle Class I molar relationship; and ANB angle between $1^{\circ}$ and $3^{\circ}$.

The characterization of groups concerning age and gender is described in Table 1, as well as the results of the independent $\mathrm{t}$ test and chi-square test, confirming that the groups were paired as to age and gender, respectively.

Lateral cephalometric radiographs (X-ray tube, $10 \mathrm{Ma}$, $75 \mathrm{kV}$ ) were obtained by a single operator using the Orthophos 3 Ceph (Sirona, Bensheim, Germany). The radiographs were taken in the natural head position with posterior teeth in maximum intercuspation. The cephalograms were digitized and measured by the software Cef-X version 2.1.31 (CDT, São Paulo, Brazil). After registering all data, the cephalometric
Table 1 - Characteristics of experimental and control groups.

\begin{tabular}{llll}
\hline & $\begin{array}{l}\text { Class III } \\
\text { Group }\end{array}$ & $\begin{array}{l}\text { Class I } \\
\text { Group }\end{array}$ & \\
\hline & Age (years) & & $\mathrm{p}$ (t test) \\
\hline Mean & 21.76 & 21.88 & \\
Standard deviation & 3.89 & 3.50 & \\
Minimum age & 18 & 18 & 0.90 \\
Maximum age & 29.83 & 30 & \\
\hline & Genders & & $\mathrm{p}$ (chi-square) \\
\hline Male & 13 & 12 & 0.60 \\
Female & 24 & 22 & \\
\hline
\end{tabular}

points of interest were delineated, and measurements were supplied by the software.

The magnification level of the lateral cephalograms was corrected by the software. All cephalometric tracings were performed by a single examiner and checked by another examiner.

To simplify the interpretation of data, the linear and angular variables were divided into four groups of measurements: vertical skeletal variables (NS.Gn, SN.Ocl, SN.GoMe, SN.GoGn, FMA, LAFH, anterior cranial base and posterior cranial base); skeletal cephalometric variables (SNA, SNB, ANB, SND, A-Nperp, Co-A, Pog-Nperp, Co-Gn, maxillomandibular differential); dental cephalometric variables (1.1, 1.NS, 1-Orbit, 1.NA, 1-NA, 1.NB, 1-NB, 1-NPog, IMPA, 1-ANperp, 1-Apo); skeletal and soft tissue profile (FNPog, NA.Pog, H.NB, H-nose, Pog-NB, E menton, nasolabial angle).

The SNA and SNB angles were used for evaluation of the different skeletal combinations of Angle Class III malocclusion in the Class III group, as described in Table $2^{4}$.

For intra-examiner error evaluation, 17 lateral cephalograms were randomly selected, retraced, re-digitized and re-measured by the same examiner, after a period of 1 month. The casual error was calculated according to the Dahlberg formula $\left(\mathrm{Se}^{2}=\sum \mathrm{d}^{2} / 2 \mathrm{n}\right)$ and the systematic error with a dependent t-test, at $\mathrm{p}<0.05$.

Means and standard deviations for the cephalometric variables were calculated for each group. Since the data presented normal distribution, the independent $t$ test $(p<0.05)$ was applied for comparison of skeletal, dental and soft tissue characteristics between Class III and Class I groups.

Statistical analyses were performed with the SAS ${ }^{\circledR}$ software version 9.1.3. (SAS Institute Inc., Cary, NC, USA).

Table 2 - Interpretation of SNA and SNB values for determination of skeletal combinations of Angle Class III malocclusion.

\begin{tabular}{lll}
\hline Angle & Values & Interpretation \\
SNA & $<80^{\circ}$ & Retruded maxilla \\
SNA & $80^{\circ} \geq 84^{\circ}$ & Well-positioned maxilla \\
SNA & $>84^{\circ}$ & Protruded maxilla \\
SNB & $<78^{\circ}$ & Retruded mandible \\
SNB & $78^{\circ} \geq 82^{\circ}$ & Well-positioned mandible \\
SNB & $>82^{\circ}$ & Protruded mandible \\
\hline
\end{tabular}




\section{Results}

No systematic errors were detected in this study. Concerning the casual error, only the 1-orbit variable presented disagreement between the first and second measurements $(3.27 \mathrm{~mm})$.

The Class III individuals showed significant differences in the cephalometric characteristics, except for vertical skeletal variables (Table 3 ).

In the Class III group, the patients presented retrusion of the maxilla in relation to the cranial base, but with adequate size; the mandible presented normal size and protrusion; the soft and skeletal profiles were concave. The maxillary incisors were protruded and buccally tipped and the mandibular incisors were retruded and lingually tipped in relation to the Class I group.

Table 4 shows the different combinations between maxillomandibular relationships in the Class III group. There was greater prevalence of mandibular prognathism.

Table 3 - Results of the independent $t$ test for comparison of cephalometric characteristics between the Class III and Class I groups.

\begin{tabular}{|c|c|c|c|c|c|}
\hline \multirow[t]{2}{*}{ Variables } & \multicolumn{2}{|c|}{$\begin{array}{l}\text { Class III } \\
(n=37)\end{array}$} & \multicolumn{2}{|c|}{$\begin{array}{l}\text { Class I } \\
(n=34)\end{array}$} & $p$ \\
\hline & \multicolumn{5}{|c|}{ Vertical skeletal variables } \\
\hline NS.Gn & 63.56 & 3.82 & 65.35 & 3.28 & $0.02^{*}$ \\
\hline SN.Ocl & 12.71 & 6.03 & 13.18 & 3.82 & 0.35 \\
\hline SN.GoMe & 33.55 & 6.64 & 34.08 & 4.66 & 0.34 \\
\hline SN.GoGn & 30.00 & 6.46 & 31.43 & 5.01 & 0.12 \\
\hline FMA & 24.56 & 6.99 & 25.71 & 5.04 & 0.36 \\
\hline Anterior cranial base & 74.54 & 3.95 & 73.65 & 3.38 & 0.12 \\
\hline Posterior cranial base & 32.97 & 6.00 & 32.84 & 4.65 & 0.45 \\
\hline \multirow[t]{2}{*}{ LAFH } & 70.23 & 6.99 & 68.25 & 5.22 & 0.07 \\
\hline & \multicolumn{5}{|c|}{ Skeletal cephalometric variables } \\
\hline SNA & 83.72 & 4.19 & 85.41 & 4.41 & $0.052^{*}$ \\
\hline SNB & 84.26 & 4.14 & 82.77 & 4.48 & $0.07^{*}$ \\
\hline ANB & -0.53 & 1.37 & 2.51 & 0.28 & $0.00^{*}$ \\
\hline SND & 80.94 & 3.43 & 78.44 & 3.51 & $0.00^{*}$ \\
\hline A-Nperp & 2.35 & 4.37 & 2.77 & 4.46 & 0.32 \\
\hline Co-A & 91.39 & 5.86 & 91.75 & 4.95 & 0.38 \\
\hline Pog-Nperp & 8.05 & 7.85 & 0.85 & 7.97 & $0.00 *$ \\
\hline Co-Gn & 127.60 & 7.66 & 120.02 & 6.46 & $0.00^{*}$ \\
\hline \multirow[t]{2}{*}{ Maxillomandibular differential } & 35.94 & 5.96 & 28.64 & 4.05 & $0.00 *$ \\
\hline & \multicolumn{5}{|c|}{ Dental cephalometric variables } \\
\hline 1.1 & 135.55 & 11.27 & 127.21 & 10.37 & $0.00^{*}$ \\
\hline 1.NS & 111.69 & 8.22 & 109.55 & 5.88 & 0.11 \\
\hline 1-Orbit & 7.20 & 6.03 & 4.50 & 4.25 & $0.01^{*}$ \\
\hline 1.NA & 27.94 & 6.80 & 24.24 & 5.42 & $0.00^{*}$ \\
\hline 1-NA & 5.67 & 2.36 & 4.61 & 1.83 & $0.02^{*}$ \\
\hline 1.NB & 17.16 & 6.96 & 25.25 & 5.98 & $0.00 *$ \\
\hline 1-NB & 3.90 & 2.16 & 6.94 & 2.31 & $0.00 *$ \\
\hline 1-NPog & 3.59 & 2.75 & 6.18 & 2.94 & $0.00^{*}$ \\
\hline IMPA & 79.25 & 6.61 & 89.14 & 7.74 & $0.00 *$ \\
\hline 1-ANperp & 7.25 & 2.08 & 6.28 & 2.11 & $0.04^{*}$ \\
\hline \multirow[t]{2}{*}{ 1-Apo } & 3.80 & 2.84 & 3.30 & 2.46 & 0.20 \\
\hline & \multicolumn{5}{|c|}{ Skeletal and soft tissue profile } \\
\hline FN-Pog & 94.15 & 3.26 & 90.51 & 3.88 & $0.00^{*}$ \\
\hline NA.Pog & -2.80 & 3.63 & 5.76 & 2.64 & $0.00^{*}$ \\
\hline H.NB & 3.24 & 3.91 & 7.15 & 3.69 & $0.00^{*}$ \\
\hline H-nose & 11.85 & 4.22 & 8.77 & 3.58 & $0.00 *$ \\
\hline Pog-NB & 1.70 & 2.12 & 1.11 & 1.54 & $0.09 *$ \\
\hline E menton & 9.44 & 2.05 & 7.64 & 2.06 & $0.00^{*}$ \\
\hline Nasolabial angle & 91.58 & 15.53 & 96.11 & 15.67 & 0.09 \\
\hline
\end{tabular}


Table 4 - Prevalence of the different combinations between maxillomandibular relationships in the Class III group.

\begin{tabular}{lccc}
\hline & \multicolumn{3}{c}{ Maxillomandibular relationship } \\
\cline { 2 - 4 } & $\begin{array}{c}\text { Retrognathic } \\
\text { maxilla and } \\
\text { well-positioned } \\
\text { mandible }\end{array}$ & $\begin{array}{c}\text { Retrognathic } \\
\text { maxilla and } \\
\text { prognathic } \\
\text { mandible }\end{array}$ & $\begin{array}{c}\text { Well-positioned } \\
\text { maxilla and } \\
\text { prognathic } \\
\text { mandible }\end{array}$ \\
Prevalence & - & & \\
$\mathbf{n}$ & 7 & 5 & 25 \\
$(\%)$ & $(18.9 \%)$ & $(13.5 \%)$ & $(67.6 \%)$ \\
\hline
\end{tabular}

\section{Discussion}

Class III malocclusion is a disorder with morphological characteristics that are variable in different ethnic groups ${ }^{2}$. Knowledge of these characteristics in different groups is fundamental for a customized diagnosis and accurate treatment planning. This study was designed to achieve more specific information on the Class III malocclusion in Caucasian Brazilian individuals.

Most vertical skeletal variables in the Class III group presented values without statistically significant differences compared to the Class I group, indicating a tendency of balanced growth. The identification of mandibular prognathism and vertical growth pattern impairs the treatment prognosis. When the patient with Angle Class III malocclusion presents balanced growth, the therapeutic possibilities are considerably increased ${ }^{11}$. These results differ from most reports in the literature demonstrating a tendency of vertical growth for patients with Angle Class III malocclusion ${ }^{12,15-16}$.

The length of anterior and posterior cranial bases did not present statistically significant differences between groups. These results also differ from previous authors, who reported reduced length of the anterior and posterior cranial bases for individuals with Class III malocclusion ${ }^{15,17}$. Guyer et al. ${ }^{16}$ observed an elongated posterior cranial base in individuals with Angle Class III malocclusion.

Similarly, the angle of cranial deflection did not present statistically significant difference between the two groups. The literature highlights that this angle is reduced in individuals with Angle Class III malocclusion, leading to a more vertical positioning of the posterior cranial base ${ }^{17}$.

The present results indicate balanced growth of the cranial base. It should be highlighted that these results are similar to those obtained by Farias et al. ${ }^{18}$, who assessed the early cephalometric characteristics of Class III malocclusion in Caucasian Brazilian children and also did not observe changes in cranial base growth and angle.

This finding is clinically positive, because the orthodontist does not have therapeutic resources to act on these structures ${ }^{2,12,19-20}$.

The divergences observed for the growth pattern and cranial base between this study and the literature may be related to differences in facial morphology observed in the different ethnic groups ${ }^{2}$. Analysis of studies evaluating the relationship between the cranial base spatial configuration and the associated malocclusion indicates that the results are different and often contradictory ${ }^{12,15}$.

Concerning maxillary anteroposterior positioning (SNA), the Class III group presented statistically significant maxillary retrognathism in relation to the sagittal positioning of this bone base in the Class I group. This result corroborates the findings of Ellis and McNamara ${ }^{14}$, Guyer et al. ${ }^{16}$, Clerck et al. ${ }^{19}$ and Moyers et al. ${ }^{20}$. However, the linear maxillary anteroposterior positioning (A-NPerp) was similar between groups.

Caution is required when interpreting this result, because the A-Nperp measurement is linear (in $\mathrm{mm}$ ), and thus the difference between maxilla and mandible should be considered. The divergence between angular and linear results for maxillary positioning may be partly explained by the greater difficulty in locating reference points of the Frankfort plane, because it involves bilateral structures. Also, changes in cranial base inclination or length should be considered.

The maxillary length did not present statistically significant difference between the two groups. Similar outcomes were also reported by Ellis and McNamara Jr. ${ }^{14}$, Guyer et al. ${ }^{16}$, Farias et al. ${ }^{18}$, Clerck et al. ${ }^{19}$ and Moyers et al. ${ }^{20}$.

Concerning the mandible, the present findings agree with the reports of several authors ${ }^{13-14,16,20-21}$ who demonstrated that, in Angle Class III malocclusions, the mandible was protruded in relation to the cranial base and its size was increased.

The ANB angle was used as a definitive selection criteria, thus it was expected to observe statistically significant difference between groups concerning this variable.

In the Class III group the maxillary incisors were protruded and buccally tipped and the mandibular incisors were retruded and lingually tipped. This fact demonstrates the natural compensation of the inadequate maxillomandibular relationship, which is expected in individuals with this malocclusion. When the treatment planning indicates dental compensation, the orthodontist must be aware of this natural compensation to evaluate whether some movement is still possible in this direction. These results corroborate previous findings in the literature ${ }^{2,14-16,20}$.

Individuals in the Class III group presented a concave soft tissue profile, with a more anterior menton position. These findings agree with the studies of Bui et al. ${ }^{2}$, Ellis and McNamara Jr. ${ }^{14}$, Guyer et al. ${ }^{16}$ and Moyers et al. ${ }^{20}$.

Differential diagnosis of the skeletal pattern should be considered for treatment planning. Easily, the Class III malocclusion may involve three different maxillomandibular relationships: retrognathic maxilla and well-positioned mandible; retrognathic maxilla and prognathic mandible; and well-positioned maxilla and prognathic mandible. In this study, the percentages were $18.9 \%, 13.5 \%$ and $67.6 \%$, respectively. These results are close to those described by Ellis and McNamara $\mathrm{Jr}^{14}$.

Most individuals (67.6\%) presented Class III malocclusion due to anteroposterior mandibular excess. This morphology of the Angle Class III malocclusion impairs the treatment and worsens the prognosis, even in patients with growth potential. This occurs because the mandibular growth 
is essentially endochondral, thus being more prone to genetic determinations and less susceptible to changes promoted by orthopedic appliances. Recently, Bayram et al. ${ }^{22}$ showed positive association between the polymorphism of the growth hormone receptor gene and the mandibular prognathism, confirming the genetic component to the development of Class III malocclusion. In individuals with Angle Class III malocclusion with evident maxillary involvement, early treatment has been more effective because the maxillary sutures are formed by intramembranous ossification, thus being more susceptible to environmental influences.

It should be emphasized the importance of establishing the treatment plan considering not only the cephalometric characteristics of the patient, but also the facial analysis.

\section{References}

1. Janson G, Souza JEP, BarrosSEC, Andrade Junior P, Nakamura AY. Orthodontic treatment alternative to a Class III subdivision malocclusion. J Appl Oral Sci. 2009; 17: 354-63.

2. Bui C, King T, Proffit W, Frazier-Bowers S. Phenotypic characterization of Class III patients. Angle Orthod. 2006; 76: 564-9.

3. Hamdan AM, Singh V, Rock W. Perceptions of dental aesthetics of Class III and anterior open bite malocclusions. Angle Orthod. 2012; 82: 202-8.

4. Staudt CB, Kiliaridis S. Different skeletal types underlying Class III malocclusion in a random population. Am J Orthod Dentofacial Orthop. 2009; 136: 715-21.

5. HuhAet al. Epigenetic influence of KAT6B and HDAC4 in the development of skeletal malocclusion. Am J Orthod Dentofacial Orthop. 2013; 144: 568-76.

6. Nikopensius T et al. A missense mutation in DUSP6 is associated with Class III malocclusion. J Dent Res. 2013; 92: 893-8.

7. Xue F, Wong RW, Rabie ABM. Genes, genetics, and Class III malocclusion. Orthod Craniofac Res. 2010; 13: 69-74.

8. Ko JM, Suh YJ, Hong J, Paeng JY, Baek SH, Kim YH. Segregation analysis of mandibular prognathism in Korean orthognathic surgery patients and their families. Angle Orthod. 2013; 83: 1027-35.

9. Cruz RM, Hartsfield JK Jr, Falcão-Alencar G, Koller DL, Pereira RW, Mah J, Ferrari I, et al. Exclusion of Class III malocclusion candidate loci in Brazilian families. J Dent Res. 2011; 90: 1202-5.

10. Uribe LMM, Vela KC, Kummet C, Dawson DV, Southard TE. Phenotypic diversity in white adults with moderate to severe Class III malocclusion. Am J Orthod Dentofacial Orthop. 2013; 144: 32-42.

11. Sobral MC, Habib FAL, Nascimento ACS. Vertical control in the Class III compensatory treatment. Dental Press J Orthod. 2013; 18: 141-59.

12. Choi H, Kimb J, Yoo SE, Kwon JH, Park K. Cephalometric characteristics of Korean children with Class III malocclusion in the deciduous dentition. Angle Orthod. 2010; 80: 86-90.

13. Kuramae M, Magnani MBBA, Pereira Neto JS, Nouer DF, Nouer PRA. Cephalometric evaluation of Class III malocclusion by a modified TweedMerrifield analysis. Braz J Oral Sci 2005; 4: 680-4.

14. Ellis E; McNamara Jr JA. Components of adult Class III open-bite malocclusion. Am J Orthod. 1984; 86: 277-90.

15. Ishii NDT, Hunt NP. Craniofacial differences between Japanese and British Caucasian females with a skeletal Class III malocclusion. Eur J Orthod. 2002; 24: 493-9.

16. Guyer EC, Ellis EE, McNamara Jr JA, Behrents RG. Components of Class III malocclusion in juveniles and adolescents. Angle Orthod. 1986; 56: 7-30.

17. Berger OPDA, Marchioro EM, Rizzato SMD, Lima EMS. Comparative study of linear and angular measures of the cranial base in skeletal Class I and III malocclusion. Rev Odonto Cienc. 2011; 26: 126-32.
18. Farias VC, Tesch RS, Denardin OVP, Ursi W. Early cephalometric characteristics in Class III malocclusion. Dental Press J Orthod. 2012; 17: 49-54.

19. Clerck H, Nguven T, Paula LK, Cevidanes L. Three-dimensional assessment of mandibular and glenoid fossa changes after bone-anchored Class III intermaxillary traction. Am J Orthod Dentofacial Orthop. 2012; 142: 25-31.

20. Moyers RE, Riolo ML, Guire KE, Wainright RL, Bookstein FL. Differential diagnosis of Class II malocclusions. Part 1: Facial types associated with Class II malocclusions. Am J Orthod. 1980; 78: 477-94.

21. Deguchi T, Katashiba S, Inami T, Foong KWC, Huake CY. Morphologic quantification of the maxilla and the mandible with cone-beam computed tomography. Am J Orthod Dentofacial Orthop 2010; 137: 218-22.

22. Bayram S, Basciftci FA, Kurar E. Relationship between P561T and C422F polymorphisms in growth hormone receptor gene and mandibular prognathism. Angle Orthod. 2014; 84: 803-9. 